\title{
Process Education in Computer Graphics
}

\author{
David R. Forsman, Kathryn Holliday-Darr, Michael Lobaugh \\ Penn State Erie, The Behrend College
}

\begin{abstract}
:
Changes in the student culture have dictated that we need to change our approach to teaching. These changes have made it necessary for us to reevaluate our teaching methods and how we present material to our students. Because we desire to improve our students' performance and find a way to have the student be more prepared for class we decided to apply a process education approach to our instruction. Process education is "an educational philosophy which focuses on building students' learning skills" (in all domains) and developing "self-growers."(1) A "self-grower" is an individual that develops the ability to learn beyond the presented material and actively seek a higher level of understanding. ${ }^{(1)}$ The graphics faculty at Penn State Erie has adopted this philosophy for all graphics classes, and has begun applying process education techniques in $1^{\text {st }}, 2^{\text {nd }}$, and $5^{\text {th }}$ semester engineering technology graphic courses. This paper will detail the implementation of these techniques and discuss the outcomes and effectiveness of this teaching approach. For example, to encourage reading, open notebook quizzes were given for each reading assignment. This method reinforces the study and cognitive skills by having the students write notes on issues that would normally be difficult for them to remember. Initially, the students reported back that their note taking ability was weak which resulted in poor quiz scores. Realizing this was an issue that effected students, an exercise was developed in how to read a technical textbook and take effective notes. The result of this was that students became aware of their weakness early on in the class and activities could be undertaken to aid them in improving in those areas.
\end{abstract}

Introduction:

Incoming first year students deal with many adjustments their first year. One of the most difficult transitions the Penn State Erie, The Behrend College engineering students must make is adjusting to the level and quality of work required in a short amount of time. The sharper students say they are used to hearing information repeated over and over until all of the students in the class understand the material. For this reason, they had to study very little, if at all, in high school. Now their college instructors expect them to take notes, read a technical textbook, figure out material on their own, manage their time, etc. Other universities have also noted that more students are being required to take remedial classes in English and Math as a prerequisite for admission to college as full time students. ${ }^{(2,3)}$ This indicates students are not as prepared as in the past and may signal other problems such as a poor attitude towards learning and a weak work ethic. These students and their college instructors are often frustrated. How can we as instructors help these students smoothly make the transition from being a passive learner to an active learner? Several engineering faculty attended a one-day workshop on process education. Process Education is another name for active learning which is "an educational philosophy which focuses on building students' learning skills (in all domains) and developing "self growers"". (1) "Active Teaching takes the position that the purpose of teaching is greater than the limits of the subject 
matter taught." (4) The engineering graphics faculty returned to campus and tried a few new activities in their classes and were very excited with the results. To learn more about process education a three-day workshop was organized. Dan Apple, president of Pacific Crest, conducted this workshop. Pacific Crest is an educational consulting and publishing company that puts on multi-day "institutes" educating educators in process education.

Most Penn State Erie Plastics Engineering Technology (PLET) and Mechanical Engineering Technology (MET) students are working towards a four-year bachelors degree. These students need to retain the computer-aided-design (CAD) knowledge learned their first year in order to be able to apply it in a junior level CAD class (detailed later in this paper). They also need to use the knowledge gained in other computer aided analysis courses, such as ANSYS, internships, and on the job after they graduate. It has been noted that student's application of this material at the junior level has been mediocre at best. Having attended a number of process education workshops during the spring and summer of 2000, it was decided implementation of active learning exercises might be the best way of addressing these deficiencies. Armed with the information learned in the workshops the graphics faculty jumped into revamping the graphics courses with both feet.

This paper is divided into sections detailing how process education teaching techniques were implemented into different level graphics classes. Each section will detail the course, how the course was taught in the past, the active learning activities introduced, the results of these changes and plans for future semesters. Suggestions for anyone considering similar changes are detailed at the end of this paper.

\section{Process Education in Computer Graphics - METBD 110}

Background:

Introduction to Graphics and Solids Modeling (METBD 110) is a first semester freshmen class for all students enrolled in the PLET and MET programs in both the associate and bachelors programs offered at Penn State Erie, The Behrend College. This class is a three-credit course, which meets five hours per week in a supervised lab setting. Since it is a first semester course, there are no prerequisites and there are no assumptions that the student has any sort of graphics or CAD background from high school. This course is currently being taught using Pro/ENGINEER ${ }^{\circledR}$ (Pro/E), which is the main CAD program used at Penn State Erie. During the fall semester of 2001, five sections were taught using three different instructors. All instructors followed the same syllabus and taught the class in essentially the same manner.

The main goals of METBD 110 were as follows: First, to give the students a firm back ground in the basics of graphics - sketching 2D views, isometric views and dimensioning rules following AMSE/ANSI standards. Second, the concepts of solid modeling using Pro/E, which included menus, constraints, dimensioning, orientation and the use of all "create/feature" options as well as creating drawings with dimensions from a solid model. 
The text used for the course was Modern Graphics Communication, Giesecke, Mitchell, et al, as this traditional text covers the basics of sketching and dimensioning. Our teaching of CAD has evolved over about a fifteen-year period. We have not found a textbook that covers material in a fashion that suits our course topics. Therefore students download material from the instructor's website on each aspect that is covered. The class is structured with a lecture at the start of class followed by practice and homework.

\section{Major Changes Implemented In The Fall Of 2001:}

1. Rewrote syllabus using 21-step process for designing a course including key objectives, etc. ${ }^{(5)}$ In the end, a five page document was produced detailing both student and instructor responsibilities. (http://engr.bd.psu.edu/holidar/html-110/110syl.html)

2. A new grade distribution was established reflecting the addition of office visits, assessment and notebook requirements. The distribution was as follows: Sketching - 30\%, Dimensioning - 20\%, Solid Modeling - 45\% and Office visits/Notebook/Journals - 5\%.

3. Student groups were assigned early in the semester and changed periodically. Each group consisted of four students. During class, the student groups compared the previous homework assignment and compared notes. Each group was then assigned one or two of the homework problems to draw on the board. The class, as a whole, would then comment on the problems and make the necessary changes.

The reason for this approach was the fact that an individual student may miss key topics. By communicating within a group, each student was able to refresh the material from the other group participants.

Student journal entries indicated the students enjoyed the group sessions. How it impacted learning is unknown, but it might have enhanced student satisfaction. Sixty seven percent of students felt in-class group work was beneficial, while fourteen percent were neutral. Students realized working with other people could be difficult. For example, one person may end up doing all of the work and it was difficult to not take offense to positive criticism. They also realized working with other people could also be advantageous, such as if a group learned to work well together and listened and considered other's ideas', they benefited from the different levels of expertise.

4. Students were required to write a weekly journal on what they learned that week. There were nine questions to be answered.

A weekly journal was used as a form of communication on several levels. The rationale was to enhance the topics the students learned; by writing down lessons learned during the week, including perceived strengths, weaknesses and any insights. It was also a means of communicating issues, improvements, and concerns from the student to the instructor. Thirty eight percent of the students said the journals helped them assess themselves. For example, 'need to schedule time better', 'recognized strengths and weaknesses', etc. Ten percent were neutral. Most felt they already adequately assessed themselves, and the journal was a waste 
of time. The students also viewed the journals as busy work stating there were too many questions, they were tired of the same questions each week and they doubted the instructor was reviewing them. This tended to decrease the importance of the journals over time. Towards the end of the semester, very few journals were turned in.

5. Activity sheets were used in place of homework assignments. Homework assignments typically stated the problem to complete, without reviewing any reason or goal. The activities were designed such that each one stated why the activity was important and the material it covered. It also listed learning objectives, what the student should learn from the activity, performance criteria, or what the student must demonstrate during the activity, and what resources were available to the student to complete the activity. This was followed by a plan or problem that contained the actual problem with pertinent information to complete properly.

The reason for writing the assignments as activities in this fashion was that by fully explaining these topics to the students, their interest in completing the assignments would improve. It was the instructors' hope that knowing the importance of the assignment would encourage the students to better understand the material and how to use it in completing the activity.

The results showed a significant portion of the students skipped over the Why, Leaning Objectives, Performance Criteria, and Resources and only read the Plan or problem. Some students even failed to carefully read and follow the Plan, resulting in a poor grade for the activity.

Since a text was not used for the CAD portion of the class, course material was located on the Web. Changes and updates for the course material were continuous and too often done just before class. This did not allow the students time to download the material and prepare prior to class. Many times the students were spending the first 10 minutes of class printing out the material needed for class.

6. How to Read a Technical Textbook activity was added. This activity was designed to allow the students to experience how to read a technical book. This was accomplished by assembling the students in a group with their textbooks and following Pacific Crests reading methodology. ${ }^{(5)}$ Each paragraph was read and discussed by a different student. Other students were allowed to help explain the text or figure as needed.

The rationale was if the students read and studied the reading assignment before class, less time could be spent lecturing, giving more time to work on activities in class. However, most students did not read before coming to class or they read the text like a novel, once through, and then could not understand why they did not understand the material. By following the reading methodology as a group, the students experienced the proper way to read a technical textbook.

Ninety percent of students viewed this activity as beneficial, although there was no way to measure the effectiveness of this one activity. Student suggestions were to move this activity to a Supplemental Instruction (SI) session that is available for this course and make the activity twice 
as long. It should be noted the SI session is voluntary and done outside of class, so if this was done, a majority of students would not participate or benefit.

7. Since organization was key to this course, especially because the CAD portion of the course relied heavily on the instructors' handouts, the students were required to keep an organized notebook.

Students do not take their third CAD class until their junior year. Therefore it was necessary for them to assemble a reference manual so they would be able to easily locate material they forgot. Notebooks have been required for several years, but the majority of students did not understand the benefit of an organized notebook and resented having to keep one. We needed to change their attitude about notebooks and prove to them that an organized notebook was an important survival tactic.

The students were required to purchase a 3" 3-ring binder to hold 3 courses of graphics material. Students were allowed to organize their notebooks as they saw fit, as long as it made sense, had sufficient labeled tabs, etc. Open notebook quizzes were designed and implemented through out the course, showing the benefits of an organized notebook.

After the semester ended, ninety-four percent of students said it was worth having the instructor check their notebook during the scheduled one-on-one meeting times, and one-hundred percent indicated the organized notebooks were beneficial, as it made it extremely easy to refer back to notes, examples, etc. Seventy six percent of the students indicated they were planning on keeping organized notebooks for future classes.

8. Times for In-Office Meetings with students were established and these meeting were worth $5 \%$ of the total grade for the course.

The rationale for the inclusion of a grade for Office visits/Notebook/Journal was to encourage the participation of the assessment portion of the class through office visits. It was also an opportunity for the instructor to interact with the students on a more personal basis and to talk to each student about their progress in the course, other classes, and career choices.

One office visit every three weeks was required to both review progress and to determine steps for improvement (assessment). It was the instructor's opinion that some students had no clue as to why they were doing poorly, or what they could do to improve their performance. Therefore these meetings were designed to enhance the communication between student and instructor. It was hoped the visits would aid the student in understanding their strengths and weaknesses and result in improved overall class performance.

Eighty-six percent said the office visits were worth their time as the instructor and student were able to keep track of progress, go over mistakes and have the opportunity to meet one-on-one to ask questions about specific problems.

While it is not possible to say the students who utilized the office visits the most did better in the course than fellow students, we can say the students who made the office visits were probably 
the more motivated ones. Students who made from three to five office visits had an overall grade average of $84.3 \%$. Students who made two office visits had an average grade of $75.5 \%$. Students who made only one office visit had an average grade of $69.7 \%$, and students who never met with the instructor had an average grade of $63.5 \%$. Students suggested the first two meetings be schedule for 10 minutes and the last two meetings be scheduled for 15 to 20 minutes.

9. Quizzes on reading assignments were routinely given. One of the issues the instructors were dealing with was student class preparation. It was hoped that open note quizzes at the start of class would insure the students read material before coming to class, practiced reading a technical textbook and taking good notes from a text. The quizzes were web based and gave the students immediate feedback as to which questions they answered correctly and what their final quiz grade was.

Eighty-five percent of the students felt the quizzes on the readings encouraged them to read before class.

10. Pre and Post assessment tests were used to guage students' perception of their own performance level as a 'learner' and a 'self-grower' at the beginning and end of the course. ${ }^{(5)}$

The rationale for this exercise was to make students aware of the different levels of learning and to assess which level they were at. After the pre-tests, the majority of the students said they were surprised with the results and were excited about learning skills that would improve their performance levels.

After the post-tests, students discovered that under the category Performance Levels for Learners, forty-one percent stayed the same, forty-one percent improved and eighteen percent went down. Typical student comments were "(I) liked seeing where I had grown and had not grown", and "(The) previous assessment of myself was more optimistic than was true."

Under the Performance Levels for Self-Growth category sixty-three percent stayed the same, twenty-six percent improved and eleven percent went down. One student stated, "I think I've gained some more insight (more realistic insight)".

Student Reaction of Changes:

Across the Penn State system, two main questions are asked of students: Rate the overall quality of the course and rate the overall quality of the instructor. Students answer the questions by selecting a value using a seven-point scale, where 1 is poor and 7 is excellent.

SRTE (Student Rating of Teaching Evaluations) for Fall 2000 showed the changes made to this class caused the evaluation of the course to go down .9 and the evaluation of the instructor to go down 1.1. 


\section{Changes For Next Fall:}

While the instructors feel they are on the right track relative to implementing the basic concepts of process education into the course, several changes need to be made. Minor changes would be to increase the amount of time for each office visit from 10 minutes to 15 minutes, give more importance to the journals and office visits by increasing the grade portion for the office visits to $10 \%$, reduce the number of journal questions to 3 or 4 and periodically change them.

The major issues were the frustration at the end of the course about the amount of out of class time required on the instructors' part, and also the speed at which solid modeling concepts were introduced. Process education is not supposed to sacrifice content for process. But this did happen. For example, several methods of presenting the CAD material were tried. The students liked having the instructor talk about the concept first, demo an easy example, and then allow the students to duplicate the same problem before starting their homework. This left less time to complete homework in class. While this was one problem; in hindsight, there were several other changes made to this course that also compounded the problem. For one, the semester was only a fourteen-week semester as compared to a normal fifteen-week semester. The instructors also wanted to make sure the students had a better understanding of correct way to model a part and properly add dimensions and constraints in the part file, so more time was taken to ensure they understood this and how to fix mistakes without starting over. The bottom line is - there is a strong possibility that this course was over scoped to start with. We also need to make sure the course is fully designed and organized before the semester begins.

Process Education in Computer Graphics - METBD 111

Background:

Applied Solids Modeling (METBD 111) is a second semester freshmen class for all students enrolled in the PLET and MET programs in both the associate and bachelors programs offered at Penn State Erie, The Behrend College. This class is a three-credit course, which meets five hours per week in a supervised lab setting. Students must successfully complete METBD 110, before being allowed to enroll in METBD 111. This course is an extension of METBD 110 and will cover topics such as sectioning, auxiliary views, working drawings, threads and fasteners, tolerancing, relations, top down modeling which is a methodology for modeling parts in the context of an assembly, etc.

Being a spring course and an extension of METBD 110, the course will be run similar to METBD 110, with a few modifications. One of the modification is to allow the students to choose whether they wanted the instructor to continue demonstrating examples after each lecture followed by everyone working the example at the same time, or allow them to form groups and use the instructor's notes to model the examples on their own. After the first experience of working in teams, the students have been in $100 \%$ agreement of letting them figure out the examples on their own. They are staying on task, having better discussions, asking better questions, etc. 
Process Education in Computer Graphics - METBD 306

Background:

Computer Aided Design (METBD 306) is a junior level class taken by both $5^{\text {th }}$ and $6^{\text {th }}$ semester Plastics Technology (PLET), and Mechanical Engineering Technology (MET) students. This is a three-credit course, where three hours/week are allocated for supervised lab and two hours/week for lecture. Its prerequisites are Introduction to Graphics and Solids Modeling (METBD 110), Applied Solids Modeling, (METBD 111) and Computer Programming (COMPSC 201). Up to this point, the students CAD background has been in SolidWorks ${ }^{\circledR}$ in both METBD 110 and 111 at the freshmen level. The reason that the students have a SolidWorks ${ }^{\circledR}$ background is that prior to a switch to Pro/E, this was the CAD package the freshmen used for solid modeling basics. Starting next year, all students taking METBD 306 will have had used Pro/E in METBD 110 and 111. The students are not required to take a CAD course during their sophomore year. This course has been taught using the same methodology for the last five years.

At one time there was a real interest expressed by the majority of students in learning to use a high-end solid modeling package. The fact that a good number of our graduates were being offered high paying jobs because of their expertise with Pro/E made the course easy to teach. A robust economy over the last decade, where students only need a piece of paper stating they have earned a degree in order to land a first job coupled with the fact that solid modeling has become somewhat of a mature technology has somewhat changed the attitude of a significant number of students. This attitude seems to be that solid modeling is simply another one of those classes they are required to "sit through".

CAD systems have always been taught "hands on" (active learning), as there is no way one can learn to use a CAD system by watching someone else use it. Student satisfaction in the course has been going down over the last few years. A seminar attended during the spring of 2000 helped the instructors focus on the fact that new and different techniques would be necessary to help the students take ownership of the course material and establish long term learning habits. After all, CAD systems have been changing since they arrived on the scene and will continue to change throughout the student's working career.

The main goals of the class were: Modeling industry-specific parts using Pro/E specific to the plastics and mechanical industry depending on semester, the automation and optimization of designs using Pro/E and understanding bench marking, CAD system selection, associated costs and its relationship to the engineering design process. The general problem from the students' point of view, as related by anonymous comment sheets during the course evaluation process, was there should be less time allocated to lecture and more time to lab. In other words, anything that did not have to do with Pro/E was a waste of time. The students perception of the class was the course was simply learning what button to push; CAD system selection, case studies of why corporations selected specific CAD systems, etc., had no place in the course. This in spite of the fact that knowledge of the background of CAD systems might be terribly useful to them after they graduated than what button do you push now. 
The original grade distribution was lab and homework assignments - $60 \%$, unannounced quizzes - $20 \%$ and final exam - $20 \%$ of the course grade. This distribution was chosen to help emphasize the importance of the material covered during the lectures. No text was used, due to lack of one specific enough to the material covered in the course.

Since Pro/E is new to almost all students, this requires a review of solid modeling basics with the Pro/E interface to bring students up to speed. There are a few select students who already have a heavy background in Pro/E that makes the first few weeks painfully boring for them. The class week generally follows the following format: One lecture/demonstration on Pro/E functionality, one lab and one lecture on general CAD related topics. A liberal lab attendance policy was followed where students did not need to attend lab. There was $20 \%$ grade reduction for late labs, up to three days. Beyond three days, no credit was given. Students complained they ended up staying up all night the day before assignments were due. The instructor spent countless hours marking up lab assignments, trying to give partial credit for work incomplete or poorly done.

The decision was made to change the format of the course in order to affect the students work habits, and try to make the students more accountable for their work product while at the same time trying to increase perceived student satisfaction for the course.

Major Changes Implemented In The Fall Of 2001:

1. Rewrote the syllabus using the 21-step process for designing a course including key objectives, measurable learning outcomes and a knowledge map. ${ }^{(5)}$ The result was a fourpage document that spelled out in detail what was expected from both the student and the instructor. (http://engr.bd.psu.edu/METBD_306_m/METBD_306_m/Syllabus_METBD306.html)

2. Students decided on grade distribution (modified at mid-semester). This was done during group discussions and voted upon by the class as a whole. The students decided upon the following: Lab Assignments - 55\%, In Class Activities and Quizzes - 15\%, Final Exam $10 \%$ and Journal, Notebook and Office Visits - 20\%.

The rationale behind this change was to allow students control of the class, in other words to start to take ownership of the course. The end result was mixed as there were a fair number of students who when writing their final assessment of the course stated that students should not have any control over the class. The instructor should simply dictate to the students and the students should do what has been required. Being in charge places some responsibility on the students and there are a number of students who are happier simply doing what they are told.

3. All assignments were done using a "Level" methodology that was simply a series of stepped assignments, from simple to complex. This was set up in the following manner: A level 7 (7 points out of a possible 10) assignment was Basic material - Levels of Learner Knowledge as defined by Pacific Crest as 1 and $2 .{ }^{(5)}$ Next was a level 8.5 assignment (8.5/10) which contained more advanced material, Level of Learner Knowledge 3 and finally a level 10 $(10 / 10)$ assignment which was a higher order material, Level of Learner Knowledge 4 
(problem solutions require that learners be able to analyze and perform problem solving) and Low Level 5 (new knowledge requires learners to perform research and synthesize). ${ }^{(5)}$

The rationale behind this change had to do with the original methodology of grading labs. Previously, the instructor, in trying to decide to what degree the student performed the lab assignments, spent an inordinate amount of time. Most students would only do select portions of the assignment, realizing they would receive partial credit. The problem we tried to fix was that students would understand and take responsibility for the work they produce.

The result of level type assignments was that students knew exactly what was expected of them to obtain a specific grade on assignments and forced them to take responsibility for their work product. Students basically knew what their grade was (or the maximum their grade could be) before turning in an assignment. It also decreased the amount of time required to grade assignments by the instructor. There was also a reduction in negotiation of partial credit after an assignment was returned to the student.

4. Minor mistakes on a lab assignment were costly; each mistake was assessed $5 \%$. This prevented students from turning in a sloppy level 10 assignment, hoping they would receive partial credit that would still be above the level 8.5 assignment. Significant mark down on mistakes on detail drawings convinced students they did not want to continually make the same mistakes again. An example would be showing hidden lines in sectional views when not necessary.

5. Lab attendance became mandatory. Students were permitted to leave lab early by turning in current week's assignment. Attendance was taken near the end of lab. Failure to attend, or not stay the entire class period, resulted in a $15 \%$ lab grade reduction.

The problem we were trying to fix had to do with students poor time management skills. One would think juniors could allocate time to tasks and not wait until the last minute to begin a computer project. However, the students had a tendency to blame the instructor for the fact that the student was up all night working on an assignment, when in fact the student had skipped lab.

The net result was that very few labs were turned in late. Required lab attendance forced the students to start work on projects when they were assigned which enabled students to ask for help during lab. This helped reduce but not eliminate students working all night to complete assignments just before they were due. The instructor also saw an increase in the number of students coming to instructor's office for help as the students realized they had problems before the due date.

6. Weekly writing of assessments and two office visits became required. The assessments were E-mailed to the instructor weekly for his review and possible comments. The office visits were to review progress and discuss any outstanding issues or problems the student might have. 
The rationale behind the visits was better communication between student and instructor. The assessments were an aid to the student to help them increase understanding of their own strengths and weakness to improve performance.

The result was mixed. Some students felt they gained valuable insights from writing the assessments; others felt it was simply a waste of time and they received nothing from assessing themselves.

Some stick had to be used to "force" the office visits and writing the assessments, so the students were graded on attendance of these visits as well as the quality and improvement of the assessments. Note the students had done their own weighting of this portion of the class. The students had weighted it fairly high (20\%), as they thought this would be an easy grade, therefore the instructor had to be conservative on evaluation of notebooks and office visits due to fact that this was the first time this methodology was used and there was bound to be some problems, as it was fairly open ended.

\section{Student Reaction of Changes:}

SRTE (Student Rating of Teaching Evaluations) for Fall 2001 showed the changes made to this class caused the evaluation of the course to go down .6 and the evaluation of the instructor to go down 9 .

The majority of the open-ended course evaluation questions were left blank, leaving the instructor confused as to what the problem in the class really was. At the beginning of the spring semester, an administrator that was well versed in process education visited a class that was composed of all the prior semesters METBD 306 students. The purpose of this visit was to obtain clearer student reactions to METBD 306. Some comments students made were a function of how the class was scheduled. They felt that three separate one hour labs would be better than one three hour lab period, as they did not like experiencing frustration over a long period. Some students felt that the higher-level lab assignments were too demanding and required too much time to complete. Students complained they would never use some things they learned in lecture and felt the lectures were disorganized.

\section{Changes That Will Be Made METBD 306:}

Dan Apple, the president of Pacific Crest, made a visit to Penn State Erie at the end of the fall 2000 semester. SRTE scores and comments along with student assessment comments were reviewed. From those discussions, the following changes need to be made:

Student assessments need to be simplified and less redundant. Students need to apply their performance criteria against what is required by the engineering profession. This should allow the student to see the direct relationship between their current performance and what will be asked of them in industry. There needs to be a first day activity where students define what qualities are desirable of an engineering technologist in industry. These items then become benchmark points in their assessments. 
The student's ability to decide on the grade distribution for the course will be done on an individual basis, rather than a class basis. The students will be given a suggested distribution, and will only be able to deviate from these values by a set amount. They will be able to modify (optimize) these values later in the semester. The suggested distribution will be Lab Assignments: $45 \%+20 \%$, In Class Activities and Quizzes: 15\% +/- 5\%, Homework: 15\% +/5\%, Final Exam: 15\% +/- 5\% and Journal, Notebook and Office Visits: 10\% +/- 5\%.

Publish the evaluation technique for attending office visits on time, degree of organization of a notebook, quality of assessments and the fact that these are submitted on time. All the "specifications" will be detailed up front so the students know what to expect.

Even though students did not really complain about the higher level assignments, it appeared some of the activities should be more open ended rather than having students research on their own to solve a specific problem. This brings up the issue of instituting a team project that becomes the dominating factor in the class. The project should exceed the ability of any individual person in the group to force interactivity and shared responsibility between group members. This approach was used in the past, but was abandoned in favor of exposing students to more of the higher end capabilities of the CAD system. Starting in the fall of 2002, all students taking METBD 306 will have had all of their CAD experience in Pro/E, allowing this course to dispense with introductory material and simply focusing on more advanced topics. This shift in what material is covered will allow the inclusion of a semester team project.

A midterm assessment should be performed where students are asked what changes should be made to the current course. Assuming the students take this seriously, and come up with suggestions that can actually be implemented (changing the hours the course meets is not an option), to institute some of these changes.

All lecture material must be directly related to some assignment or in-class activity. Most students seem to think this is a "what button do I push" class, therefore the one class per week on non-Pro/E related CAD seems a waste to a fair number of students. An assignment will be handed out that the student will have no prior background in the material. The students will quickly learn that the "answer" to the problem is a function of paying attention and taking notes during the lectures and in-class activities.

Downplay group discussions as technology students seem to view this as a disorganized activity where the students are doing the instructors work. No reference will be made to such terms as Bloom's Taxonomy, active learning, or self-grower which students feel have no place in CAD classes.

Suggestions For Others Contemplating Changing Their CAD Classes:

Do not make too many changes at once. While it is difficult to only make select changes to a course and not have it appear disjointed, making wholesale changes disrupts a student's general perception of a class. Most students (except first semester freshmen) know what is expected of them based on how classes were taught previously. Students do not like it when somebody 'moves the cheese' too far. ${ }^{(6)}$ 
Expect a drop in student evaluations if major changes are made to a class. Since the process education approach requires greater involvement by the students, there is going to be a subset that resists having to perform at a higher level than in the past. The net effect is that these students will lash out at instructors during the evaluation process, and reducing the overall average of the evaluations. This is usually in spite of the instructor's best effort to keep in tune with the students' thinking. It appears that a fair number of students will tell the instructor what the instructor wants to hear (or write what the instructor wants to read), all the while thinking the opposite. It is not until the instructor has no "power" over the student, will the student respond honestly or vengefully depending on the situation.

Technology students expect to be told what to do. Explaining the theory behind process education to these students falls on deaf ears and students view these discussions as a waste of time that have nothing to do with CAD systems. A better approach might be to simply state facts such as: "You are now juniors, therefore I expect a higher level of work from you. It is also time for you to learn how to be a leader and not a follower. Make the best decisions you can and live with the consequences." These are process education concepts put in concrete terms that the average technology student should be able to relate to. When evaluating and assessing the students, hold them to a level they would be expected of a new hire in industry.

Conclusion:

While the results were not quite what was expected or hoped for, we still feel it is in the students best interest to pursue the integration of a more active learning environment into CAD related classes. As instructors, we need to continue to identify the issues that we have as ineffective facilitators' and resolve the problem.

Popkin indicates that one of the principles of the active learning process is: Courage: Students must learn it is okay to fail and to try again, even if it means to fail again. ${ }^{(4)} \mathrm{We}$, as instructors must maintain that same philosophy, in other words if the changes we make do not have the results that we expect, we must not give up but keep trying.

1. Pacific Crest (2002). Process Education. Retrieved January 12, 2002, from http://www.pcrest.com/phil.htm

2. Onwuegbuzie, A. J., Slate, J.R., Schwartz, R.A. (Mar/Apr 2001). "Role Of Study Skills In Graduate-Level Educational Research Courses". The Journal of Educational Research. Vol. 94. Issue 4. Washington, D.C. [H.W. Wilson - Educ].

3. Holton, J.M. (1998). "High School course choice, Performance and Readiness for college. Frederick County Public High School Graduates Enrolling at Frederick Community College. Retrieved January 14, 2002, from CSA - Internet Database Service http://www.csa3.com/htbin/ids52/procskel.cgi?fn=f_quick.html\&ctx=/wais/idstmp/ctxAAAab59_a\&cat=so $\underline{\text { cialsci }}$

4. Popkin, M.H. (1994). "Active Teaching Enhancing Discipline, Self-Esteem and Student Performance". Active Parenting Publishers, Inc. Atlanta, Georgia. 16.

5. Apple, D.K., Krumsieg, K. (2001). Teaching Institute Handbook. Pacific Crest Inc. Corvallis, Oregon. 
6. Johnson, S. (1988). "Who Moved My Cheese? An Amazing Way to Deal with Change in Your Work \& in Your Life". Penguin Putnam Inc, New York, New York.

DAVID R. FORSMAN

David R. Forsman is an Instructor of Engineering at Penn State Erie. He received his B.S. in Engineering Technology from the Pennsylvania State University and his M.E. in Manufacturing Systems Engineering from SUNY, Buffalo. He has been involved with engineering computer analysis since 1974. He has experience in teaching Computer-Graphics, Programming, CAD and Rapid Prototyping for the last 19 years.

\section{KATHRYN HOLLIDAY-DARR}

Kathryn Holliday-Darr has been an Instructor of Engineering Graphics at Penn State Erie since 1985. She received her B.A. in Industrial Arts at the University of Northern Colorado, and her M.S. in Industrial Arts Education at Buffalo State SUNY. Her research and teaching interests include engineering graphics, visualization, and working with freshmen enrolled in engineering technology programs. She is the author of Applied Descriptive Geometry.

\section{MICHAEL LOBAUGH}

Michael Lobaugh is a Lecturer in Engineering at Penn State Erie. He received his B.S. in M.E. at the University of Illinois in 1986 and his M.S. in Engineering Management at the University of Massachusetts in 1997. Prior to joining the faculty at Penn State, he worked at Lord Corp. and Babcock and Wilcox in various engineering and management roles. He has experience teaching computer-graphics, manufacturing processes and QC. 